\title{
PHILOSOPHICAL-LEGAL ANTHROPOLOGY \\ AS AN INSEPARABLE ELEMENT \\ OF MODERN INTELLECTUAL DISCOURSE
}

\section{Irina Matviienko ${ }^{1}$}

DOI: https://doi.org/10.30525/978-9934-588-15-0-102

Abstract. The article deals with the question of the philosophy of law and philosophical-legal anthropology as the basis of intercultural and interstate dialogue of the modern world. The philosophy of law as a science aims to explain the importance of law for developing the outlook, to consider the content and meaning of law for man, including him/her in the system of human values. In the philosophy of law, the latter appears as a way of human existence. The purpose of the study is to identify the fundamental importance of philosophy of law in the system of sciences, as well as to carry out a comparative analysis of concepts such as philosophical-legal anthropology, the legal person and legal freedom. The philosophy of law defines law within the framework of fundamental changes in the world, culture, state, man. Trying to create a holistic approach to the concept of law, this discipline creates a theoretical model of legal reality, taking into account human and social specificities in a constantly changing world; it is these conditions in which the concept of law for man and the world as a whole is formed and developed, as well as defined. The primary method of philosophical-legal research is the method of critical analysis. The rationalistic philosophical-legal methodology is used to define the concept of law and comprehend reflexively the legal problems through the method of logical deduction, by which the concept of law on the ground of anthropological ideas is formulated; thus, we can define the concept of law through theoretical and practical research. Democracy does not depend on the rights, freedoms, principles presented, but above all on the society of subjects who understand what the right to freedom and liberty is, and who are able to exercise this right. Only the subject has the capacity to think, and therefore can be regarded as the goal of all social and legal policy. Since the capacity for reasoning is not only the ability to think critically, but also the ability, based on feelings, partly on

${ }^{1}$ Candidate of Philosophy, Associate Professor,

National University of Life and Environmental Sciences of Ukraine, Ukraine 
intuition, it would be logical enough to conclude that to develop and improve, such an ability requires twice as much effort from the individual and his/her will, and of course, from the society as well. Self-esteem is engendered in every person because of the will of everyone in the moment when another world is confronted with one's own spirit, and we solve our own life problems. Only a self-respecting individual can respect the right and create a law that would not be degrading to humans. Through the dialectic of the unity of rights and duties, which has the idea of freedom in its manifestation, one can understand that in essence a person has duties only to the extent he/she has rights.

\section{Introduction}

Modern society is evolving fast enough to show us that the social processes that take place in it are closely linked to progress, which is inseparable from the notion of a legal culture that leads to legal stability, both on the scale of national legal relations and international, which is extremely important today. On the basis of the general methodology and the intersection of such essential facts of the development of the modern globalized world as the interaction of the world legal systems, their dialogue and the need for mutual understanding, the practical significance of the philosophical analysis of the legal apprehending this problem is determined. In addition, an important issue is the formation of a single legal space in international relations, since the issue of human rights and freedoms is gaining importance at the interstate level.

Law has a powerful force in influencing social processes, both domestically and internationally. The style of legal thinking, the values and methodological orientations that are dominant in the current legal world, today depend on peace in the world. This determines the need to improve legal thinking, the study of its concepts and categories, methodology and principles, as well as a comparative analysis of the philosophical ideas of such well-known philosophers of law as I. Kant, G.W.F. Hegel, J. Fichte, F.W.J. Schelling and the study of legal hermeneutics, to put it bluntly, is the subject of the philosophy of law.

It is natural that the growing influence of the importance of legal factors on the development of civilization, which is expressed primarily by the fact that modern law subjects are facing the problem of self-understanding and understanding in society, that is why the relevance of this study is stipulated by to the need for a philosophical level of awareness of the problem of law. Legal systems of the world exist at different levels of functioning and deve- 
lopment, which is closely linked to the personal development of both persons at law and societies in general, which are at different levels of development of legal paradigms. That is why the philosophy of law is intended to perform the function of a knowledge integrator both in the system «person - law» and in the system «society-law», while determining the worldview, methodological, structural and legal foundation of the philosophy of law.

Scientific novelty of the results obtained is determined by the fact that today there is an intensive development of the philosophy of law in general, and of philosophical-legal anthropology in particular, which is caused by the need for humanization of the legal sphere, protection of the rights and freedoms of every person, both in modern Ukraine and Europe. Legal anthropology focuses its scientific research on the definition and research of the idea of legal person (person of law), as the main category of modern legal reality. The successful development of philosophical-legal anthropology as a section of the philosophy of law, is directly related to the issues of combating contemporary stereotypes of legal thought, which is certainly relevant today.

Purpose of the study is to identify the fundamental importance of philosophy of law in the system of sciences, as well as to carry out a comparative analysis of concepts such as philosophical-legal anthropology, the legal person and legal freedom.

To achieve this goal, the author defined the following tasks:

- to determine the importance of the philosophy of law in the system of sciences;

- to find out the subject, functions and methods of the philosophy of law;

- to carry out a comparative analysis of such philosophical-legal concepts as the legal person and legal freedom.

The methodological basis of the study is the general scientific principles and methods of research, which include:

1) the method of comparative analysis has become the methodological basis for studying the worldview changes in understanding the content and originality of the phenomena of law and philosophy, freedom and duty;

2) the method of textual analysis allowed to reveal the implicit authorial sense of philosophical texts devoted to the consideration of the problem of philosophical-legal anthropology and philosophy of law.

3) hermeneutical method, as a method without which interpretation and re-interpretation of texts is impossible. 


\section{Philosophy of law in the system of sciences}

Philosophy of law is a complex discipline, which also includes anthropology, because it is directly related to man. It includes sociology, because it has to do with society, and political science, because the political condition of the state influences the formation of laws, and of course philosophy and jurisprudence. As a rational scientific study, this discipline is in rather close relations with the various legal sciences, and especially with the «theory of law». In 1870 , Adolf Merkel introduces the concept of «theory of law» as analogous to the concept of «philosophy of law». Over time, the development of society and the heterogeneity of the sciences, prompted the emergence of a large number of disciplines, which began to exist as independent, so it happened with the science of law, which proved itself as a theory of law. For some time, there was such a discipline as the encyclopedia of law, that is, a discipline in which all legal concepts were systematized, but more often the term was understood as a summary of all legal disciplines and areas.

Relying on rational principles and methods in the world cognition, philosophy and law are similar, but one must not forget that the former and the latter often deal with non-rationalistic concepts. In addition, philosophy is fundamentally different in law than jurisprudence.

For jurisprudence, the world is a set of facts that have an objective structure; the main purpose of science is to describe the structure, trying to accurately uncover the laws of the world. Law sciences are trying to work out a clear logical algorithm for understanding the concept of law, while exploring the origins and mechanisms of law formation, find patterns of its functioning and conditions of its application in the life of man, society and the world. Ideally, legal science deals only with an objective description of legal facts. The philosophy of law is not limited to the systematization, collection and explanation of legal facts, the way the law deals with it. Its main task is a critical reflection on the dominant tendencies of the development of law and the state, the study of legal reality in the perspective of the necessary and universal principles and values of existence that determine the formation of the essence of the human personality. The major task for the philosophy of law is to show the importance, necessity and value of law in the life of everyone and the world at large.

Law is the powerful root of the social, personal and spiritual-cultural life of any nation, as I.A. Ilyin writes, that is why those who considered law in the 
direction of jurisprudence alone, do not look into the essential depths of legal existence. "Law can only set general, abstract rules, and therefore it speaks in its norms only in general about people, about features in general, about actions, relationships, powers and responsibilities in general, highlighting one side and properties as essential and leaving others without attention» [4, p. 408]. No thinker who has reasoned about man, society, the world, history could do without the topic of law, and no theorist of law can bypass philosophy.

Philosophy of law has a significant place in the system of philosophical disciplines, traditionally it belongs to the field of practical philosophy, which also includes the doctrines of morality, aesthetics, philosophy of politics and others, and theoretical such as epistemology, logic and the doctrine of being (existence), etc. The philosophy of law is a form adopted by philosophy that reflects on the fundamental principles of culture and law. This means that the features of philosophical knowledge extend to the philosophy of law, which includes a philosophical and legal ontology that examines the specifics of legal existence; philosophical and legal epistemology, which explores the peculiarities of legal knowledge; philosophical and legal axiology that deals with legal values; philosophical and legal anthropology, which is related to the problems of manifestation of human and law, and also includes the ethics of law, etc. Today, the philosophy of law works closely with such disciplines as political science of law, sociology of law, economics of law, psychology of law, cultural studies of law, etc. As a result of such interaction within the framework of the philosophy of law, separate sections are formed, where philosophical and legal anthropology, philosophical and legal cultural studies are addressed, etc.

\section{The subject, functions and methods of philosophy of law}

Law is a complex multidimensional phenomenon that has emerged in the context of cultural, philosophical, historical, political, scientific, and religious changes in society. The philosophical approach to law is distinguished by the fact that this subject of study is considered and understood as a phenomenon of legal culture. In the modern philosophy of law, its subject is treated differently, because approaches to the definition of the legal person are as many as philosophical systems. The philosophy of law is a section in philosophical knowledge, the subject of which is not the knowledge of all things or of the world, but of law as such, which involves the consideration of the problems of 
freedom, equality, honor, justice, responsibility, crime and punishment for it, which, in fact, is closely related to the nature of man himself, his existence in society and nature. The main purpose of the philosophy of law is to discover the meaning of the concept of «law» with all the consequences that follow in the process of studying law through the prism of man.

The philosophy of law examines the meaning of the concept of law, examines its basis and essence, its value and meaning, as well as what kind of role it plays in the life of man, state, society and the world at large.

Considering the philosophy of law as a philosophical and legal discipline, we should clearly define its functions: 1) ideological function of the philosophy of law - helps in shaping the legal world and legal culture, without which it is impossible to create a legal society. Reflecting the attitude of man to law, view-points on the meaning and purpose of life, the connection of its interests and needs of society, social and legal reality, the philosophy of law is the basis of human social orientation. It defines people's worldview approach to the evaluation of legal phenomena, comprehends and substantiates legal ideals, determines the strategy for their achievement. In the categories of philosophy of law there is a reflection of the worldview problems of jurisprudence, a conceptual apparatus is developed to compare and analyze different types of legal worldview. 2) The methodological function of the philosophy of law is determined by the role played by philosophical knowledge for the majority of specific sciences. Knowledge of the sense and meaning of law, which the philosophy of law works on, determines the vectors of research in studying the specific legal forms and is the basis of the general theory of law. The philosophy of law reveals and formulates the most general laws, concepts and principles of knowledge of legal reality. Philosophical-legal methodology determines the directions of scientific research, gives the possibility of orientation in an endless amount of legal facts and objective processes that take place in the world. 3) Axiological function of the philosophy of law - its main task is the development of legal values such as equality, freedom, justice, as well as the idea of the ideal of law and interpretation from the standpoint of this ideal of legal reality. 4) The educational function of the philosophy of law is of particular importance today, which implies the ability to understand the high humanistic content of one's own activities, to philosophically substantiate one's own theoretical position and make a practical decision that determines the 
high professionalism and honesty of a lawyer. This justification is largely determined by the attitudes and principles of lawyers, whose formation is particularly influenced by philosophy.

The philosophy of law as a science aims to explain the importance of law for developing the outlook, to consider the content and meaning of law for man, including him/her in the system of human values. In the philosophy of law, law appears as a way of being human. Considering this science at such an angle, we get a fairly broad definition of the philosophy of law, so some researchers wanting to define and specify the philosophy of law, considering this concept as a methodological basis of jurisprudence, whose main task is to study the global legal-state categories, which are the basis of all legal sciences. Such discussions do not appear to be empty, because the very concept of law does not have a clear, unambiguous definition, but is of a variable nature. But, if we generalize and try to identify the problems facing the philosophy of law, in the first place these are: the specifics of law, its essence, its methodology, ways of philosophical comprehension of law in general, the normative power of law, legal culture and legal consciousness, the nature of the crime and punishment for the crime, human rights and duties, the law and its place in the country, the essence of international law, etc. Thus, the philosophy of law defines law within the framework of fundamental changes in the world, culture, state, man.

Trying to create a holistic approach to the concept of law, this discipline creates theoretical models of legal reality, taking into account human and social specificities in a constantly changing world. It is these conditions in which the concept of law for man and the world as a whole is formed and developed, as well as defined.

The main method of philosophical-legal research is the method of critical analysis. Reflexive human activity distinguishes it from the animal and is carried out in various ways depending on the level of development of culture and civilization. Part of the global development of human consciousness, knowledge, society and culture is the multi-level process of evolution of philosophical reflection. The rationalistic philosophical and legal methodology is used to define the concept of law and to comprehend reflexively the legal problems through the method of logical deduction, by which the concept of law is based on anthropological representations, so that we can define the concept of law through theoretical and practical research. Therefore, the theoretical is based on 
the potential conditions of implementation of law, the practical (empirical) uses the method of practical induction, it generalizes specific facts and forms the general concepts of law out of them. Considering this problem, we should mention one of the most influential representatives of German classical philosophy G.W.F. Hegel and his dialectical method of law study, based on the principle of ascent from abstract to specific from a single legal concepts to a system that allows you to learn the subject in its essential characteristics [3, p. 5].

The philosophy of law must function not as a generally accepted norm, but as a general system of values and regulators of human activity. G.W.F. Hegel sought to develop a single method that would be universal for both theoretical and practical understanding of law, but the philosophy of the XX century showed that finding a single method that could be applied everywhere is impossible.

It is important to note that there are currently several methods in the philosophy of law that are closely linked to different philosophical systems. Let's look at some of them. Phenomenological method is a way of revealing the content of law, which is dependent on different thoughts, words, interpretations, estimates, using the method of phenomenological reduction, that is, the rejection of the natural setting, which opposes being and consciousness. Consequently, the objective being is a priori inherent in consciousness, it finds its meaning through consciousness. Consciousness is thus a «pure consciousness» and the world is a «phenomenon of the world», that is, the correlate or of such consciousness. "The idea of law, which is freedom, as conceived by G. Hegel, is revealed in the world of law, and the sphere of objective spirit is presented as an ideal legal reality - the objectification of forms of law and freedom» [3, p. 7]. That is why phenomenology is the science of the world construction, which appears for man as an ideal thingness.

The method of hermeneutics in modern philosophy is regarded as a methodology of humanitarian and historical knowledge, which builds its theory on the understanding and interpretation of texts that are ontological. «The task of hermeneutics is to show that existence reaches the word, content, reflection only through the continuous interpretation of all meanings that are born in the world of culture» [8, p. 34]. Hermeneutics is an interpretation of signs, symbols and texts that connect a person with the natural and social environment. In the philosophy of law, this methodology is related to the idea of understanding legal reality as a set of legal texts. 
The analytical method views philosophy as an analysis of using the linguistic expressions by which philosophical knowledge and its categories are formulated. The analysis seeks to solve the fundamental problems of philosophy through conscious, meaningful rules for using the linguistic means that help to identify philosophical problems. In the philosophy of law, this method is used to study the specifics of linguistic expressions in jurisprudence to analyze legal concepts.

The structuralist method follows from the structural method that was developed in structural linguistics and only later was applied to ethnography, philosophy, and literary studies. It is based on the identification and study of structure as a set of relations, invariant under different changes. Thus, the notion of structure acquires characteristics of not just a scheme of any object, but a set of rules by which the first object can deliver the second, the third, etc. by symmetrical changes of its parts. Legal reality is seen as a symbolic form of human activity that begins to form at a subconscious level.

Developing as a scientific discipline, the philosophy of law increases the number of methods that it uses, so that completely new methods of understanding legal reality emerge. Thus, for example, the famous Russian researcher of philosophy of law V.S. Nersesyants proposed a «libertarian» method as a new philosophical and legal one. "This is a common way of legal modeling of reality on the principle of formal equality, a way of knowing reality from the position and within the given concept of law, a way of legal (formal-equal) understanding, expression, changes, qualifications and evaluation of the reality investigated» [7, p. 9]. The main principle of this method is to look at the world and reality through the prism of law. One cannot say that experiments in modern philosophy lead to usingsuch methods as synergistic one in law, by which such philosophical categories as order and chaos, law and harmony and many others are considered in a new way.

The basis for distinguishing among different types of the philosophy of law is methodology. Modern philosophy is multidimensional, just the way the modern globalized world is, which is why both the methods and the philosophy of law are characterized by pluralism.

The desire to solve fundamental theoretical problems of jurisprudence without a philosophical basis, as a rule, leads to the absolutization of external, formal aspects of law, to the separation of law from the development of spiritual culture, its values and ideals. In order to lay the foundations for under- 
standing the law, one must first determine the true cultural meaning of law, and secondly, develop a concept of law that is capable of fully reflecting that cultural significance without being limited to purely applied needs of right.

\section{Philosophical-legal anthropology}

Philosophical-legal anthropology is a separate area within the philosophy of law, which explores the relation of law and human being, reveals the idea of human rights, and their role in the life of society. Law is not possible without the legal person, that is, the person for whom, in fact, it is written, and who implements it. Man created law for himself as a necessary attribute of his/her own existence. This need was stipulated not only by pragmatic ideas, but also the need of the human spirit. P. Ricoeur wrote, "An individual is already subject of a full right before entering into a contractual relationship; he/she is inferior to real rights, which are called, respectively, natural, in exchange either for security, as in Hobbes's, or for civility or citizenship as in Rousseau and Kant» [9, p. 40].

Although everyone has the right to the law, not every person is aware of its importance for settling the relations in society. Many philosophical systems believe that «a person must be worthy of the law». This dignity is manifested both in the possibility of his/her moral consciousness and in his/ her willingness to create such a right that would correspond to the status of an independent free man. This thesis can be defined as a simple question that everyone has to ask: «What kind of person am I supposed to be in order to be worthy of the law?».

In legal practice and in the philosophy of law, the problem of the legal person is differently addressed. In legal science, a legal person is thought of as some perfect legal convention. Otto von Gierke defined: «a person as a legal concept», which is obtained as a result of a conscious abstraction of law by isolating one part of reality. He put forward a «concept» of unions of the person (individual)», among which he distinguished the state, corporations and institutions (establishments)». As Otto von Gierke argued, a corporation is a real or complex person. A union personality is a legally recognized ability of the human union, as a whole, distinct from the number of connected individuals, to be the subject of rights and duties ... About union, as well as about the individual, one can say that they exist to the extent that they are recognized by objective law» $[9$, p. 97-98]. That is why a legal entity that is not identical 
with any reality that we perceive as a holistic phenomenon, is invisible and impossible to grasp. Everyone is thought of as a legal person - artificially created by legal construction. Accordingly, once and for all, it is necessary to abandon the generally accepted world view that a living person may be a legal person. For a lawyer, «the concept of man and a person is not connected by any essential necessary connection». Only mistakenly mixing the normative method with the actual method makes the origin of the error according to which a person is identified with a legal entity, clear. However, this theory has been sharply criticized in the theory of philosophy of law. The main mistake of this theory is that the concept of «legal person», is not clearly defined. It is accepted in the sense in which it is accepted by legal practice, meanwhile this content is not clearly established. In the doctrine of the legal person, it is revealed in the general legal theory, which is relatively weak manifestation of the idea of a person as a legal figure.

Understanding the legal person as a legal construction may be sufficient to resolve certain practical issues, but it is not at all sufficient to understand the substance of the law as such. It is only for the legal subject to passively reproduce the meaning of positive law by interpreting legal rules. The importance of the doctrine of competence clearly indicates the empirical and vital boundaries of conscious existence, they are also important in explaining such legal concepts as act, error, deception, manifestation of will through other persons. The idea of a conscious, meaningful command cannot be separated from concepts such as an offense, which in its content is reduced to activities and omissions, that is, to conscious behavior. At the same time, the person who is the bearer of legal activity completely disappears when the legal theory begins to talk about legal capacity, legal entity, legal understanding. In all these cases, being a legal person and exercising law does not mean the same thing, that is, it does not mean being a legal person. If we use a subject, it does not mean to be a legal person, if we speak of a subject as a carrier, in some special sense, therefore, to be a right holder can mean not only to be a figure, but also to be recognized and to be of value under the protection of law and order.

The doctrine of the legal entity is regarded as a value element that is different from the idea of actions and activity. But historically, the term person has been formulated to include the subject. If something is recognized as having legal value, it must be of the nature of the subject of the law, the person who discloses the pre-scientific consciousness. 
In the doctrine of the legal subject, modern theory itself without realizing it reveals the worldview of existing law and its impact on the cardinal values that underlie modern legal science. The doctrine of the state as a legal entity is a kind of formulation of the protection of the value of centralized forms of public-legal authority. But this approach is not theoretically recognized. It is not enough to distinguish the idea of a person as a legal figure from the idea of a person as a value - this is, according to some scholars, the main problem of all the above theories. Both the state and society, as well as any function, construction and hypothesis can be recognized values of law and order. However, these values can neither be ethical nor legal in ideas or in their implementation. The simplest solution is the path offered by proponents of the legal method. This question cannot be resolved in any general form. The whole case depends on the nature and features of the relevant rules of positive law. «The destination of positive law is that a person, having evidently seen its objective content and its objective meaning, voluntarily obliges himself to obey its rules and to educate in this direction not only his/her conscious decisions but also his/her immediate, instinctive desires and aspirations. In such a way he/she exercises a certain spiritual acceptance of positive law, and this acceptance requires the maturity of reason and will, a particular equilibrium of the soul, because it must be realized with a clear awareness of always possible profound imperfection of positive law ... which is why it requires great sustainability, endurance and volitional discipline» [4, p. 181].

Positive law can state one thing in one case, and another - in some other case, it can attribute the abilities to some persons in one case and in another case to some other persons. In such circumstances, it makes no sense to find a solution to the question of who can be a legal entity. After all, the issue of a legal entity is closely related to the issue, obligation and responsibility, and this issue is already clearly anthropological. The legal norm is intended not only to define the duties, but also to control their performance. There are various theories that suggest that the legal person may be grass, or an object, but in our opinion, these theories of N.N. Alekseev, L.I. Petramitskyi have no grain of rationality, although they are explored by modern legal science. Contrary to these theories, we must determine that only a person can be the true legal person, not only as a physical or psychological being, but as a person, that is, the bearer of acts of recognition, a consciously mature citizen who possesses the mind and a firm memory. The true legal person 
is able to sense, desire and comprehend substantially the purpose of law and the state. One cannot be compelled to be a legal person - this opinion is relevant today, because it is an opportunity to give an adequate rational assessment of a situation that goes beyond one's personal view of the world.

Only the subject has the capacity to think, and therefore can be regarded as the goal of all social and legal policy. Democracy depends not on the rights, freedoms, principles presented, but above all on the society of subjects who understand what the right to liberty is, and who are able to exercise this right. Since the capacity for reasoning is not only the ability to think critically, but also the ability, which is based on feelings, partly on intuition, it would be logical enough to conclude that developing and improving such an ability requires twice as much effort from the individual, his will, and of course, from society as well. «The spiritual purpose of law is to live in the souls of people, «filling» its content with their experiences and thus forming in their consciousness the internal inspirations, affecting their lives and their external actions. The task of law is, notes I.A. Ilyin, to create motives for better behavior in the souls of people» [4, p. 180]. Only a free person thinks, because critical thinking is always one's own thinking process, which entails a critical and evaluative nature, questions all the information that comes to us, makes personal informed and rational conclusions. And if thought is imposed, it paralyzes our thought process, thus preventing our mind from developing. That is why it is important to identify the basic possibilities of judgment: first, the autonomous will of the individual, secondly, self-esteem, and third, the ability to treat other people as equals. The autonomy of our will and the status of a citizen define one another. "The state in itself and for itself is a moral whole, the exercise of freedom, and the absolute purpose of the mind is to make freedom truly existent», G.W.F. Hegel said in his work «Philosophy of Law». "The state is a spirit that resides in the world and is realized in it consciously. Only as inherent in the consciousness, which knows itself as an existing object, i.e. as a state» [3, p. 283]. A person who is incapable of freeing his inner will cannot be free, at best he can only be its passive participant.

Any state power should work to educate its citizens of the capacity of judgment, because it is the legal thinking process that determines the basis of the state, it is the source of power, as well as the condition of cohesion and inviolability of the state as a whole. It is impossible to make a person 
think critically, a person worthy of rights, must make his/her own decisions and be responsible for those decisions. The mistake of any tyranny, monarchy, or despondency is that they do not allow the thinking activities of their citizens. In such societies, citizens are deprived of the opportunity to think critically about the true state of affairs, about their own rights and duties, since the authorities and the state have defined everything beforehand.

To be a citizen in the true meaning of the word means to possess one's own capacity for critical thinking, to be able to give one's own judgment to everything that is happening, and at the same time to draw one's own conclusions about law, moral issues: evil and good, justice and injustice. A true citizen of his country must clearly understand what the law and rights mean, what the state is and what their main goals are. A person who is in a state of oppression cannot harmonize either his/her own life or the life of society. Another indispensable component is a sense of dignity for the citizen, which is inextricably linked to the courage that is necessarily linked to the citizen's position. A person who is deprived of these feelings is morally and politically incapacitated. Self-esteem arises in people as a result of the development of spiritual reflection and begins with the fact that one realizes himself as an integrity that must be upheld in the struggle, respect for oneself is connected with the ability of people to assert their own rights and freedom. But at the same time, every subject of society and state must always define for himself two main guidelines: first, no person should concede to the fundamental values that make a person a human being; secondly, everyone should see the limits of their rights and not to try to increase them wherever it is potentially impossible.

Self-esteem is born in every person because of the will of everyone in the moment when another world is confronted with one's own spirit, and we solve our own life problems. Only a self-respecting entity can respect the law and create a law that would not be degrading to humans.

Reflecting on the concept of freedom, which has a close connection with the concept of law, we cannot limit this concept as something defined within the limits of social reality. Freedom is achieved not so much as a result, but as a constant process that manifests itself in the three basic coordinates of each person's life, namely: first, as the relationship between subjects, that is, when a person engages in social relations with other people (when our activity is determined by the norms of rights and duties, and it is through social relations that we determine that someone has power over others, and 
this is clearly regulated not by violence, not coercion, but solely by law, which in turn is regulated by duties), secondly, as the relation between subject and object when one does not separate himself from natural integrity (in this case, the measure of freedom is determined by the unity of will and necessity, and such an understanding is correlated with the definition of freedom as «conscious need»), and third, as the relation of subject object - subject, when a person has power over himself, but he also knows himself by reflecting on himself (a measure of human freedom is determined by the interconnection of will and necessity, but man in relation to himself can only use his/her will).

In the moral and spiritual spheres there is no legal form of human behavior, in these spheres there are no rights and duties. Here, through the dialectic of «denial of objection», new wills and necessities emerge, which are synthesized into the concept of «duty» with aspects of law inherent in this concept. The inner world of man includes the will, necessity, conditions and means that man uses for the realization of himself. In the moral sphere, as G.W.F. Hegel points out, duties and rights «pass into one another and are combined».

With respect to those who have no responsibilities, not the right, but the will, which manifests itself in one form of permissiveness or another, is fulfilled. Parents take responsibility for establishing a human being, that is, the upbringing of a child, before other people, that is, society, while having certain rights in the process of relationships with children. When we talk about the nature of the inner, we must use the categories of will and necessity, but if we speak of the external, then we must use the concepts of «right» and «duty». That is why we can only understand freedom through the prism of necessity. Necessity can be seen as both a condition and a cause. Duty is a condition of manifestation of the external, and necessity is a condition of manifestation of the internal. Will is realized by necessity, and duty manifests through rights. And if necessity is a condition for the realization of the will (conscious human activity), then the duty is the right (a means of achieving the desired result).

In order to understand what constitutes a being of freedom, one must consider the obligation as a way of exercising and supplementing the right. Our mind cannot overcome the external separation of rights and duties. For it, the duty is not simply categorically distinct from the law, but also 
regarded as somewhat separate from the law. In the mind, right exists by itself, and duty - by itself. It is only through reason that one realizes that in the process of freedom, duty not only acts as a contradiction to law, but also as a means of exercising it, that is, identical to the concept of law. Through the dialectic of the unity of rights and duties, which has the manifestation of the idea of freedom, one can understand that in essence a person has duties only to the extent he or she has rights. According to G.W.F. Hegel, «some duty on my part corresponds to some duty on another part». Others, in turn, should respect my right.

Freedom appears as a whole divided into two opposites, the first appears as a right, the second as a duty. And if the right is seen as a measure of freedom determined by the conditions of its attainment, then the duty will then characterize the actions taken as conditions for attaining freedom. In this case, the duty will be manifested as something internal to the law, and law, respectively, as somewhat internal to the duty.

Rights and duties as opposites are both different and similar. According to G.W.F. Hegel, right is characterized by an «inherent existence of free will», and thus the right includes the existence of all definitions of freedom, which «in respect of subjective will is its duty» [3, p. 8]. Duties and rights form the whole, which has the characteristic «what is right is duty, and what is duty is right». That is why, «he who has no rights has no duties, and vice versa». If we do not accept the duty as such, then the freedom as a whole, falls apart and loses its vitality. Thus, right as a tendency manifests the essence of freedom, and the duty- of non-freedom. «In freedom it is necessary to proceed not from individuality, from single self-consciousness, but only from its essence, because this essence, regardless of whether a person knows about it or not, is realized as an independent power in which separate individuals are no more than moments... its basis is the power of the mind, which realizes itself as a will» [3, p. 284].

The right always characterizes a certain possibility, which in one way or another is predetermined, that is, becomes lawful. Man, according to G.W.F. Hegel, because he/she wants to be real, must exist personally, must limit himself/herself, that is, the person must independently determine his/ her plan of action, clear for implementation, so that the opportunities that are opened after acceptance can be used. for his/her duties. These duties in one area give a person the rights in another. 


\section{Conclusions}

Thus, the reviewed and analyzed materials prove that the topic of philosophy of law and philosophical-legal anthropology is extremely important:

- trying to create a holistic approach to the concept of law, this discipline creates a theoretical model of legal reality, taking into account human and social specificity in a constantly changing world, it is these conditions in which the concept of law for man and the world as a whole is formed and developed, as well as defined, where the main method of philosophical-legal research is presented by a method of critical analysis;

- every year the issue of the rights and duties of individuals and states as a whole becomes more and more acute, which is why the issue of philosophical appreciation of law acquires a special status;

- through the dialectic of the unity of rights and duties, which has the manifestation of the idea of freedom, one can understand that, in essence, humans have duties only to the extent they have rights.

\section{References:}

1. Arystotel (2003). Polityka [Politics]. Kyiv: Osnovy. (in Ukrainian)

2. Hehel H.V.F. (1990). Filosofiia prava [Philosophy of Law]. Moscov: Mysl. (in Russian)

3. Il in I.A. (1994). O sushchnosti pravo soznaniya [On these sence of legal consciousness]. Moscov: Russkaia Knyha. (in Russian)

4. Kant I. (2005). Lektsyi po etike [Lectures on ethics]. Moscov: Respublika. (in Russian)

5. Mariten Zk. (2007). Intehralnyi humanizm; Svoboda v suchasnomu sviti; Lyst pro nezalezhnist [Integral Humanism; Freedom in the modern world; A letter on independence]. Indiana: University of Notre Dame Press.

6. Nersesyants V.S. (2002). Filosofiya prava: libertarno-yuridicheskaya kontseptsiya [Philosophy of Law: A Libertarian-Legal Concept] Questions of Philosophy, no. 3, pp. 3-15. (in Russian)

7. Riker P. (2008). Konflikt interpretatsyy. Ocherki o germenevtike [Conflict of interpretations. Essays on hermeneutics]. Moscov: Akademicheskij Proek. (in Russian)

8. Riker P. (2002). Pravo i spravedlyvist [Law and justice]. Kyiv: Dukh i litera. (in Ukrainian)

9. Suvorov N.S. (2000). Ob yuridicheskikh litsakh po rimskomu pravu [On legal entities in Roman law]. Moscow: Statut. (in Russian) 